\title{
Hypoxia induces a functionally significant and translationally efficient neuronal NO synthase mRNA variant
}

\author{
Michael E. Ward,1,2,3 Mourad Toporsian, ${ }^{4}$ Jeremy A. Scott,,1,3 Hwee Teoh,1,2 \\ Vasanthi Govindaraju, ${ }^{4}$ Adrian Quan, ${ }^{1,2}$ Avraham D. Wener, ${ }^{1,2}$ Guilin Wang, ${ }^{1,2}$ \\ Siân C. Bevan, ${ }^{3}$ Derek C. Newton, ${ }^{3}$ and Philip A. Marsden ${ }^{3}$
}

${ }^{1}$ Division of Respirology, University of Toronto, Toronto, Ontario, Canada. 2Department of Critical Care and Terrence Donnelly Laboratories, St. Michael's Hospital, Toronto, Ontario, Canada. ${ }^{3}$ Department of Medicine, St. Michael's Hospital and University of Toronto, Toronto, Ontario, Canada. ${ }^{4}$ Meakins-Christie Laboratories, McGill University, Montreal, Quebec, Canada.

\begin{abstract}
We tested the hypothesis that induction of neuronal NO synthase (nNOS) impairs vascular smooth muscle contractility after hypoxia. nNOS protein was increased in aorta, mesenteric arterioles, pulmonary arteries, brain, and diaphragm from rats exposed to $8 \% \mathrm{O}_{2}$ for 48 hours and in human aortic SMCs after hypoxic incubation $\left(1 \% \mathrm{O}_{2}\right) \cdot \mathrm{Ca}^{2+}$-dependent $\mathrm{NO}$ synthase activity was increased in endothelium-denuded aortic segments from hypoxia-exposed rats. $\mathrm{N}^{\mathrm{G}}$-nitro-L-arginine methyl ester enhanced the contractile responses of endothelium-denuded aortic rings and mesenteric arterioles from hypoxia-exposed but not normoxic rats $(P<0.05)$. The hypoxia-inducible mRNA transcript expressed by human cells was found to contain a novel 5 -untranslated region, consistent with activation of transcription in the genomic region contiguous with exon 2. Translational efficiency of this transcript is markedly increased compared with previously described human $n N O S$ mRNAs. Transgenic mice possessing a lacZ reporter construct under control of these genomic sequences demonstrated expression of the construct after exposure to hypoxia $\left(8 \% \mathrm{O}_{2}, 48\right.$ hours $)$ in the aorta, mesenteric arterioles, renal papilla, and brain. These results reveal a novel human $n N O S$ promoter that confers the ability to rapidly upregulate $n N O S$ expression in response to hypoxia with a functionally significant effect on vascular smooth muscle contraction.
\end{abstract}

\section{Introduction}

$\mathrm{NO}$ is a multifunctional intra- and intercellular messenger affecting diverse aspects of physiology including the regulation of vascular tone (1) and neuronal (2) and renal tubular function (3). Recently, a central role for the neuronal isoform of NO synthase (nNOS, NOS1) in the integration of mammalian ventilatory and metabolic adaptations to hypoxia has been recognized (4-6). Considering the need to balance this important function with the inherent cytotoxicity of $\mathrm{NO}(7)$ and the potential for its overproduction to exacerbate hypoxic injury (8), it is not surprising that regulatory mechanisms have evolved to ensure that nNOS activity is tightly linked to tissue oxygen levels $(9,10)$.

In addition to changes in ventilation and metabolic rate, hypoxia elicits adrenergically mediated vascular reflexes that redistribute blood flow and enhance the capacity for oxygen extraction $(11,12)$. If oxygen deprivation is prolonged, however, systemic vascular smooth muscle contractility $(13,14)$ and, hence, the sympathetic responses that preserve tissue oxygen supply (15) become progressively impaired. nNOS is expressed by VSMCs $(16-18)$, and upregulation of nNOS protein by hypoxia has been

Nonstandard abbreviations used: Ach, acetylcholine; $\mathrm{CRE}, \mathrm{cAMP} / \mathrm{Ca}^{2+}$ response element; $\mathrm{EC}_{50}$, concentration of agonist required to elicit $50 \%$ of the maximum tension; Ex-1c, exon 1c; HASMC, human aortic SMC; HIF-1, hypoxia-inducible factor-1; IRES, internal ribosome entry site; L-NAME, $\mathrm{N}^{\mathrm{G}}$-nitro-L-arginine methyl ester; $\mathrm{nNOS}$, neuronal NO synthase; NOS, NO synthase; ORF, open reading frame; PE, phenylephrine; $5^{\prime}$-RACE, $5^{\prime}$-rapid amplification of cDNA ends; $5^{\prime}$ UTR, $5^{\prime}$ untranslated region. Conflict of interest: The authors have declared that no conflict of interest exists.

Citation for this article: J. Clin. Invest. 115:3128-3139 (2005). doi:10.1172/JCI20806. demonstrated in neurons and skeletal muscle $(10,19)$. The current study was therefore carried out to test the hypothesis that increased smooth muscle nNOS activity contributes to the loss of systemic vascular reactivity, which is observed after hypoxic exposure in vivo, and to determine the mechanisms by which hypoxia activates $n N O S$ expression.

Tissue/cell-specific $n N O S$ expression is primarily regulated through the use of alternate promoters that give rise to distinct mRNA species $(20,21)$. The $n N O S$ mRNAs that predominate in neurons and muscle arise through activation of promoters clustered in genomic regions considerably upstream of those that contain the translation initiation codon within exon 2 . This transcriptional organization results in mRNA species that, while encoding the same $160-\mathrm{kDa}$ nNOS protein, contain varying 5 -untranslated first exons $(21,22)$, the length and structure of which profoundly impair translational efficiency (23). In contrast, activation of promoters downstream of exon 2 can result in the expression of transcripts that utilize alternate translation initiation sites and produce truncated forms of the protein (24-26). We report here the in vitro and in vivo effects of hypoxia on $n N O S$ expression and function. Hypoxia induced the expression of an nNOS protein that migrates electrophoretically at the predicted molecular mass of the full-length protein $(10,19)$. Our results indicate that oxygen regulation of this gene involves initiation of transcription from a genomic region that is distinct from regions implicated in the constitutive and cell-restricted expression of nNOS. The results reveal the existence of a human $n N O S$ promoter that gives rise to an $n N O S$ mRNA containing a foreshortened $5^{\prime}$-untranslated region $\left(5^{\prime}\right.$-UTR) that permits 


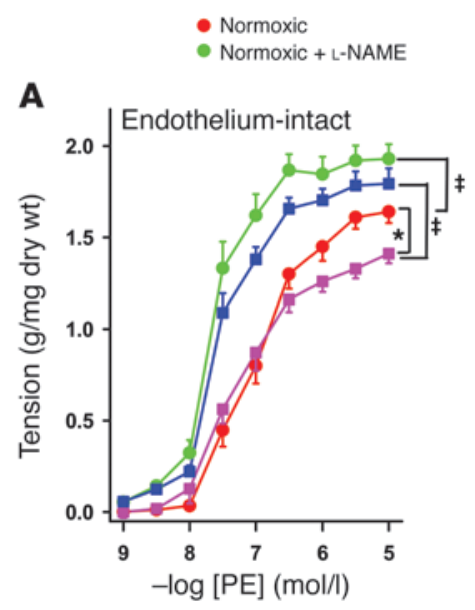

Normoxic

Normoxic + L-NAME

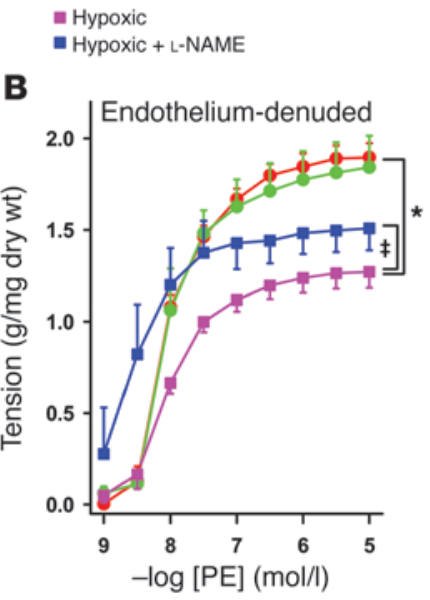

\section{Figure 1}

Concentration-response relationships for PE-induced contraction in the presence and absence of L-NAME $(10 \mu \mathrm{M})$ for endothelium-intact and -denuded aortic rings from normoxic rats $(\mathbf{A})$ and rats exposed to hypoxia for 48 hours (B) ( $n=7$ per group). ${ }^{*} P<0.05$ for differences between untreated rings from normoxic and hypoxia-exposed rats. $¥ P<0.05$ for differences between L-NAME-treated and -untreated rings from hypoxia-exposed animals (ANOVA). its rapid translation. This represents a newer model of oxygen regulation of mammalian gene expression in which alternate promoter usage not only directs transcriptional activation in a developmental stage- and tissue-specific manner but also confers the ability to rapidly alter cellular phenotype in response to a critical change in the extracellular environment.

\section{Results}

Functional studies. The effects of endothelial denudation, and NOS inhibition with $\mathrm{N}^{\mathrm{G}}$-nitro-L-arginine methyl ester (L-NAME), on the concentration-response relationship for phenylephrine $(\mathrm{PE})$ in aortic rings from normoxic rats and rats exposed to hypoxia for 48 hours are illustrated in Figure 1. The effect of L-NAME on maximum tensions and $\mathrm{EC}_{50}$ (concentration of agonist required to elicit $50 \%$ of the maximum tension) values during PE- and $\mathrm{KCl}$-induced aortic contractions are presented in Table 1 . The maximum PE- and $\mathrm{KCl}$-induced tensions in aortic rings from rats exposed to hypoxia were lower than those in rings from normoxic rats. The $\mathrm{EC}_{50}$ value was lower (i.e., sensitivity was increased) after endothelial ablation in rings from both normoxic and hypoxic animals. Removal of the endothelium increased the maximum tension during PE-induced contraction in rings from normoxic rats, whereas, as noted previously $(14,27)$, tension was greater in endothelium-intact than -denuded rings from rats exposed to hypoxia. Treatment with $\mathrm{L}-\mathrm{NAME}$ increased maximum tension and decreased the $\mathrm{EC}_{50}$ during PE-induced contraction in endothelium-intact rings from both normoxic and hypoxic animals but had no effect on the response to either $\mathrm{PE}$ or $\mathrm{KCl}$ in endothelium-denuded rings from normoxic rats. In endothelium-denuded rings from rats exposed to hypoxia, in contrast, L-NAME increased maximum tension and decreased the $\mathrm{EC}_{50}$ for both PE- and $\mathrm{KCl}$-induced contractions.

We next determined the effect of hypoxia on representative resistance vessels from the mesenteric circulation. The effects of L-NAME on the PE concentration-response relationship in endothelium-denuded mesenteric arterioles from normoxic and hypoxia-exposed rats is illustrated in Figure 2 and summarized in Table 2. As in aortic rings, the contractile response of mesenteric arterioles from hypoxic animals was reduced compared with that in the normoxic group. Maximum tension was increased in the presence of L-NAME in segments from hypoxia-exposed rats but was not significantly altered in arterioles from normoxic rats. There was no difference between L-NAME-treated segments from hypoxia-exposed rats and untreated segments from normoxic rats. Taken together, these data indicate that prolonged hypoxia induces functional deficits in smooth muscle contractility in both large conductance vessels and arterioles. Surprisingly, this effect was especially evident when the endothelium was removed. The robust effect of the NO synthase (NOS) inhibitor L-NAME indicates an important role for $\mathrm{NO}$ in this response.

NOS activity. In aortae from normoxic rats, $\mathrm{Ca}^{2+}$-dependent NOS activity was predominantly localized to the endothelium, as evidenced by elimination of the majority of this activity fol-

Table 1

Effect of $\mathrm{L}-\mathrm{NAME}$ on maximum tension and $\mathrm{EC}_{50}$ during $\mathrm{PE}$ - and $\mathrm{KCl}$-induced aortic contraction

\begin{tabular}{|c|c|c|c|c|c|c|}
\hline \multirow{2}{*}{$\begin{array}{l}\text { Contractile } \\
\text { agent }\end{array}$} & \multirow[t]{2}{*}{ Endothelium } & \multirow[t]{2}{*}{ Drug treatment } & \multicolumn{2}{|c|}{ Maximum tension ( $g / m g$ dry wt) } & \multicolumn{2}{|c|}{$-\log \mathrm{EC}_{50}(\mathrm{~mol} / \mathrm{l})$} \\
\hline & & & Normoxia & 48 h hypoxia & Normoxia & 48 h hypoxia \\
\hline \multirow[t]{2}{*}{$\mathrm{PE}$} & $\begin{array}{c}\text { Intact } \\
\text { Removed }\end{array}$ & $\begin{array}{c}\text { KHS } \\
10 \mu \mathrm{mol} / \mathrm{l} \text { L-NAME } \\
\mathrm{KHS} \\
10 \mu \mathrm{mol} / / \mathrm{l} \mathrm{L-NAME}\end{array}$ & $\begin{array}{l}1.64 \pm 0.06 \\
1.93 \pm 0.13^{B} \\
1.89 \pm 0.08^{\mathrm{C}} \\
1.85 \pm 0.17\end{array}$ & $\begin{array}{l}1.41 \pm 0.06^{\mathrm{A}} \\
1.79 \pm 0.08^{\mathrm{B}} \\
1.27 \pm 0.09^{\mathrm{A}, \mathrm{C}} \\
1.49 \pm 0.12^{\mathrm{A}, \mathrm{B}, \mathrm{C}}\end{array}$ & $\begin{array}{l}6.84 \pm 0.10 \\
7.44 \pm 0.05^{B} \\
8.02 \pm 0.06^{C} \\
8.03 \pm 0.05^{C}\end{array}$ & $\begin{array}{l}7.07 \pm 0.10 \\
7.34 \pm 0.06^{\mathrm{B}} \\
7.99 \pm 0.04^{\mathrm{C}} \\
8.54 \pm 0.05^{\mathrm{A}, \mathrm{B}, \mathrm{C}}\end{array}$ \\
\hline & & & & & \multicolumn{2}{|c|}{$\mathrm{EC}_{50}(\mathrm{mmol} / \mathrm{l})$} \\
\hline $\mathrm{KCl}$ & Removed & $\begin{array}{c}\text { KHS } \\
10 \mu \mathrm{mol} / / \mathrm{L} \text { L-NAME }\end{array}$ & $\begin{array}{l}1.66 \pm 0.14 \\
1.74 \pm 0.12\end{array}$ & $\begin{array}{l}1.34 \pm 0.04 \mathrm{~A} \\
1.86 \pm 0.08^{B}\end{array}$ & $\begin{array}{l}14.14 \pm 3.3 \\
14.19 \pm 3.0\end{array}$ & $\begin{array}{l}19.32 \pm 1.37^{\mathrm{A}} \\
14.78 \pm 1.08^{\mathrm{B}}\end{array}$ \\
\hline
\end{tabular}

${ }^{A} P<0.05$ for difference from corresponding normoxic group; ${ }^{B} P<0.05$ for difference from corresponding L-NAME-Untreated (KHS) control group; ${ }^{C} P<0.05$ for difference from corresponding endothelium-intact group. KHS, Krebs-Henseleit solution. 


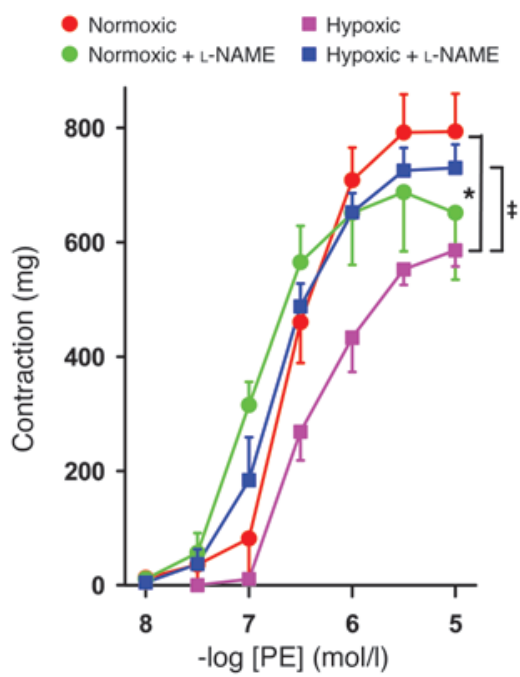

lowing endothelial ablation (Figure 3). In endothelium-denuded aortic segments, $\mathrm{Ca}^{2+}$-dependent NOS activity increased with the duration of the hypoxic exposure to reach a value equal to the total $\mathrm{Ca}^{2+}$-dependent NOS activity (Figure 3 ). This suggests a shift in the primary locus of $\mathrm{Ca}^{2+}$-dependent NOS activity from the endothelium in normoxic rats to the smooth muscle in rats exposed to hypoxia. $\mathrm{Ca}^{2+}$-independent NOS activity was negligible in all groups of rats, consistent with the absence of iNOS (data not shown).

Western blots. Western blots indicated increased levels of nNOS protein in aortae (Figure 4A), mesenteric arterioles (Figure 4B), pulmonary arteries (Figure 4C), diaphragms (Figure 4D), and brains (Figure 4E) from rats exposed to hypoxia, compared with normoxic animals. nNOS protein levels were also increased in human aortic SMCs (HASMCs) (Figure 4F) after hypoxic incubation. iNOS protein was not detected in aortic homogenates from either normoxic or hypoxia-exposed rats (data not shown).

Immunobistochemistry. The aortae of rats exposed to hypoxia for 48 hours displayed positive staining for nNOS protein in the tunica media and adventitial layers (Figure 5). nNOS immunoreactivity was not detected in the tunica media of aortae from normoxic rats.

In situ bybridization. nNOS mRNA was detected in the medial and adventitial layers of aortae from both normoxic and hypoxic rats; however, grains representing $n N O S$ mRNA transcripts were more abundant in the aortic media in the hypoxia-exposed group than in the normoxic group, in which $n N O S$ transcripts were rarely detected (data not shown). Parallel studies using $\left[{ }^{35} \mathrm{~S}\right]$-labeled cRNA probe in the sense orientation (negative control) did not yield any signal (data not shown).

\section{Figure 2}

Concentration-response relationships for $\mathrm{PE}$-induced contraction in the presence and absence of L-NAME $(10 \mu \mathrm{M})$ in endotheliumdenuded mesenteric arterioles from normoxic rats and rats exposed to hypoxia for 48 hours ( $n=6$ per group). ${ }^{\star} P<0.05$ for difference between untreated rings from normoxic and hypoxia-exposed rats. $\ddagger P<0.05$ for difference between L-NAME-treated and -untreated rings from hypoxia-exposed animals (ANOVA).

Cloning of a novel buman nNOS promoter. We and others have reported extensive 5 '-mRNA diversity for $n N O S$ mRNA species $(21,23,28)$. An important mechanism underlying this diversity was alternative use of different promoters. Therefore, we used the method of $5^{\prime}$-rapid amplification of cDNA ends (5'-RACE) and RNA isolated from normoxic and hypoxic HASMCs to characterize the structure of $n N O S$ mRNA $5^{\prime}$ termini expressed in hypoxic human cells. The design of the RACE allowed cloning of varied 5 '-sequences upstream of the region within exon 2 where translation of nNOS initiates. A total of $305^{\prime}$-RACE clones were analyzed from hypoxic cells. All clones exhibited a common $5^{\prime}$ sequence that differed from sequences of $n N O S$ mRNAs previously detected in human tissues (23). In our prior studies, we failed to identify corresponding cDNA clones (over 100 clones analyzed in human brain, testis, skeletal muscle, kidney, heart, and skeletal muscle). A total of twelve 5'-RACE clones was analyzed from normoxic HASMCs. Sequence analyses of these clones, which were very uncommon, correspond to sequences identical to the previously identified exon 1c (Ex-1c) (23).

Characterization of $\mathrm{P} 1$ bacteriophage clones representing genomic regions corresponding to the human $n N O S$ gene indicated that these unique cDNA $5^{\prime}$ termini were contiguous with genomic regions encoding exon 2 observed in previously described human cDNAs. Since stop codons are evident in all 3 translation reading frames immediately upstream of the initiating AUG in exon 2, initiation of transcription in this genomic region would not affect the encoded protein sequence. For cDNAs derived from this genomic region, transcription therefore initiates within genomic regions that represent 3 '-regions of intron 1 or exon 2 of $n N O S$ cDNAs derived from transcription initiation sites previously reported in other tissues. Although the designation as exon 2 is not technically valid for hypoxiainducible $n N O S$ mRNA transcripts in VSMCs, it will be used for descriptive purposes.

Expression of $n N O S$ promoter construct. We used an insertional murine transgenic approach to address the in vivo functional relevance of human $n N O S$ genomic sequences identified through characterization of hypoxic human VSMCs. Genomic regions flanking the $5^{\prime}$ terminus of mRNAs identified in hypoxic cells were used to direct a reporter gene (Figure 6A). Expression of the

Table 2

Effect of L-NAME on maximum tension and $\mathrm{EC}_{50}$ during PE-induced contraction in mesenteric arterioles

\begin{tabular}{|c|c|c|c|c|c|c|}
\hline \multirow[t]{2}{*}{ Contractile agent } & \multirow[t]{2}{*}{ Endothelium } & \multirow[t]{2}{*}{ Drug treatment } & \multicolumn{2}{|c|}{ Maximum tension (mg) } & \multicolumn{2}{|c|}{$-\log \mathrm{EC}_{50}(\mathrm{~mol} / \mathrm{l})$} \\
\hline & & & Normoxia & 48 h hypoxia & Normoxia & 48 h hypoxia \\
\hline PE & Removed & $\begin{array}{c}\text { KHS } \\
10 \mu \mathrm{mol} / / \mathrm{L} \text { L-NAME }\end{array}$ & $\begin{array}{l}813.6 \pm 67.6 \\
696.2 \pm 105.4\end{array}$ & $\begin{array}{l}589.3 \pm 26.7^{\mathrm{A}} \\
743.5 \pm 39.0^{\mathrm{B}}\end{array}$ & $\begin{array}{l}6.66 \pm 0.12 \\
7.02 \pm 0.08\end{array}$ & $\begin{array}{l}6.44 \pm 0.12^{\mathrm{A}} \\
6.78 \pm 0.12^{\mathrm{B}}\end{array}$ \\
\hline
\end{tabular}

AP $<0.05$ for difference from corresponding normoxic group; ${ }^{\mathrm{B} P}<0.05$ for difference from corresponding L-NAME-Untreated (KHS) control group. 


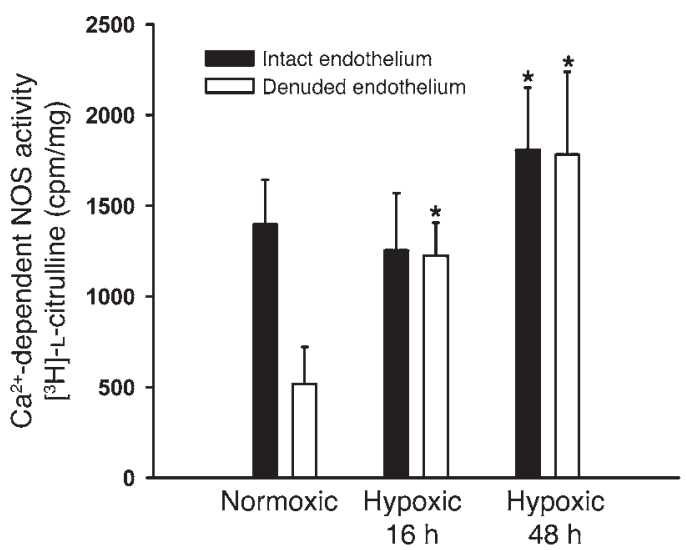

Figure 3

$\mathrm{Ca}^{2+}$-dependent NOS activity in endothelium-intact (black bars) and -denuded (white bars) aortae from rats exposed to normoxia and hypoxia for 16 and 48 hours ( $n=6$ per group). ${ }^{*} P<0.05$ for difference from corresponding normoxic control value.

nNOS/LacZ reporter transgene was not observed in normoxic control tissues from transgene-positive mice. Representative sections of renal papilla and brain are shown in Figure 6B. However, exposure to hypoxia (fraction of inspired oxygen $\left[\mathrm{FiO}_{2}\right]=0.08$; 48 hours) resulted in a qualitatively significant (all-or-none) increase in the $\beta$-galactosidase staining in epithelial cells of the renal medulla and neurons of the CNS (Figure 6B). Conversely, basal expression of the $\beta$-galactosidase reporter in the eNOS/LacZ reporter-transgenic mice in the kidneys and brain from normoxic mice was abrogated in hypoxia-exposed mice (Figure 6C). The effect of hypoxia on expression of the $n N O S / L a c Z$ reporter construct and nNOS mRNA in mesenteric arterioles, kidney, and aorta of transgene-positive mice is illustrated in Figure 7. Hypoxic exposure resulted in marked increases in the levels of these mRNAs in all 3 tissues.

$n N O S$ translation. The human $n N O S$ gene is characterized by multiple promoters that generate numerous and distinct mRNAs that vary in their 5 '-UTR sequences and which profoundly influence their translational efficiency (23). The long, complex, and highly structured $n N O S 5^{\prime}$-UTRs act as a translational impediment and prevent overexpression. We posit that 1 function of the promoter located within exon 2 is to generate $n N O S$ transcripts with short, highly translatable 5'-UTRs. This would enable the cell to rapidly induce nNOS protein expression in response to stimuli. We therefore tested the translational efficiency of varied $n N O S 5^{\prime}$-UTRs in both lysates and transfected cells. Luciferase reporter constructs were designed to reflect the native $n N O S 5^{\prime}$ UTR derived from the exon 2 -associated promoter described herein. The translational efficiency of this RNA species was compared with that of other $n N O S 5^{\prime}$-UTR sequences. Of interest, the translational efficiency of luciferase reporter constructs reflective of $n N O S$ mRNAs derived from the exon 2 promoter (Ex2Short) was increased by more than $200 \%$ in cells and more than $450 \%$ in lysates compared with the full-length $n N O S$ exon 2 (Ex2Long) (Figure 8, A and B). In comparison to a transcript derived from the common human $n N O S$ 1c promoter (Ex-1c) (29), the translational efficiency was increased more than 24 -fold. This dramatic change in translational efficiency was also observed in transiently transfected rat PC12 and hamster CHO-K1 cell types (data not shown), suggesting that this effect was not species or cell type restricted. We next sought to determine whether the translational efficiency of the nNOS mRNA derived from the exon 2 promoter (Ex2-Short) was specifically altered under anaerobic conditions, as this could explain the dramatic induction of nNOS during hypoxia. Cultured myocytes transfected with the Ex2-Short luciferase RNA construct showed no change in Firefly luciferase activity, regardless of whether cells were cultured under normoxic or hypoxic $\left(1 \% \mathrm{O}_{2}\right)$ conditions. Ex2-Short was compared with the Ex-1c and Ex2-Long mRNAs, and, similarly, no change in luciferase activity was observed under anaerobic conditions (Figure 8C). These results indicate that the nascent Ex2-Short mRNA transcripts are still efficiently translated in the setting of hypoxia.

Internal translation initiation. A select number of mRNAs have the ability to promote internal initiation of translation via cis-acting internal ribosome entry sites (IRESs) (30). We sought to determine whether an IRES was active in regulating translation of $n N O S$ mRNAs basally or during hypoxia. We constructed a series of bicistronic vectors based upon the pRF plasmid (Promega) that contains the Renilla luciferase and Firefly luciferase open reading frames (ORFs) separated by a multiple cloning site. Constructs were developed to recapitulate native $n N O S$ mRNAs derived from the exon 2 (pRFx2F), Ex-1c (pREx1cF), and Ex-1g (pRFEx1gF) promoters. Translation of the Renilla luciferase occurs in a capdependent fashion, whereas cap-independent translation of the Firefly luciferase ORF occurs only when an IRES is present within the multiple cloning site. Therefore, an increase in the Firefly/Renilla luciferase (FL/RL) ratio would indicate the presence of an IRES. We found no increase in the FL/RL ratios for any of the nNOS mRNAs tested under normoxic or hypoxic conditions (Figure 8, D and E). The bicistronic pRhrvF and pRpolioF containing the human rhinovirus IRES element and poliovirus IRES element inserted within the multiple cloning site of pRF, respectively, were transfected as positive controls for IRES activity. These studies indicate that IRES-mediated internal initiation does not occur in the $n N O S$ sequences tested.

\section{Discussion}

Vital organ oxygenation is preserved during acute reductions in oxygen delivery by sympathetically mediated vascular reflexes that redirect blood flow (12) and enhance oxygen extraction (11). In contrast, when hypoxia is prolonged (12-48 hours), the reactivity of systemic arteries $(13,14)$ and, hence, sympathetic vascular responses (15) are impaired. This will limit the ability to maintain vital organ oxygenation if substrate supply must be augmented in order to meet an increase in metabolic demand, such as may occur with a superimposed episode of hypotension or if hypoxia were to acutely become more severe. Hypoxia is known to induce changes in systemic vascular endothelial cell phenotype and perturbations in the expression of endothelialderived NO (31). Our current results indicate that the decrease in systemic vascular reactivity following longer-term hypoxia persists despite endothelial ablation. This localizes an important component of the abnormality to the vascular smooth muscle. We found that nNOS mRNA, protein, and activity levels are enhanced by hypoxia in systemic vascular smooth muscle. Importantly, the current work confirms and extends prior studies reporting that $n N O S$ mRNA and protein contribute to VSMC-derived NO, especially in disease $(1,16,18,32-34)$. This 

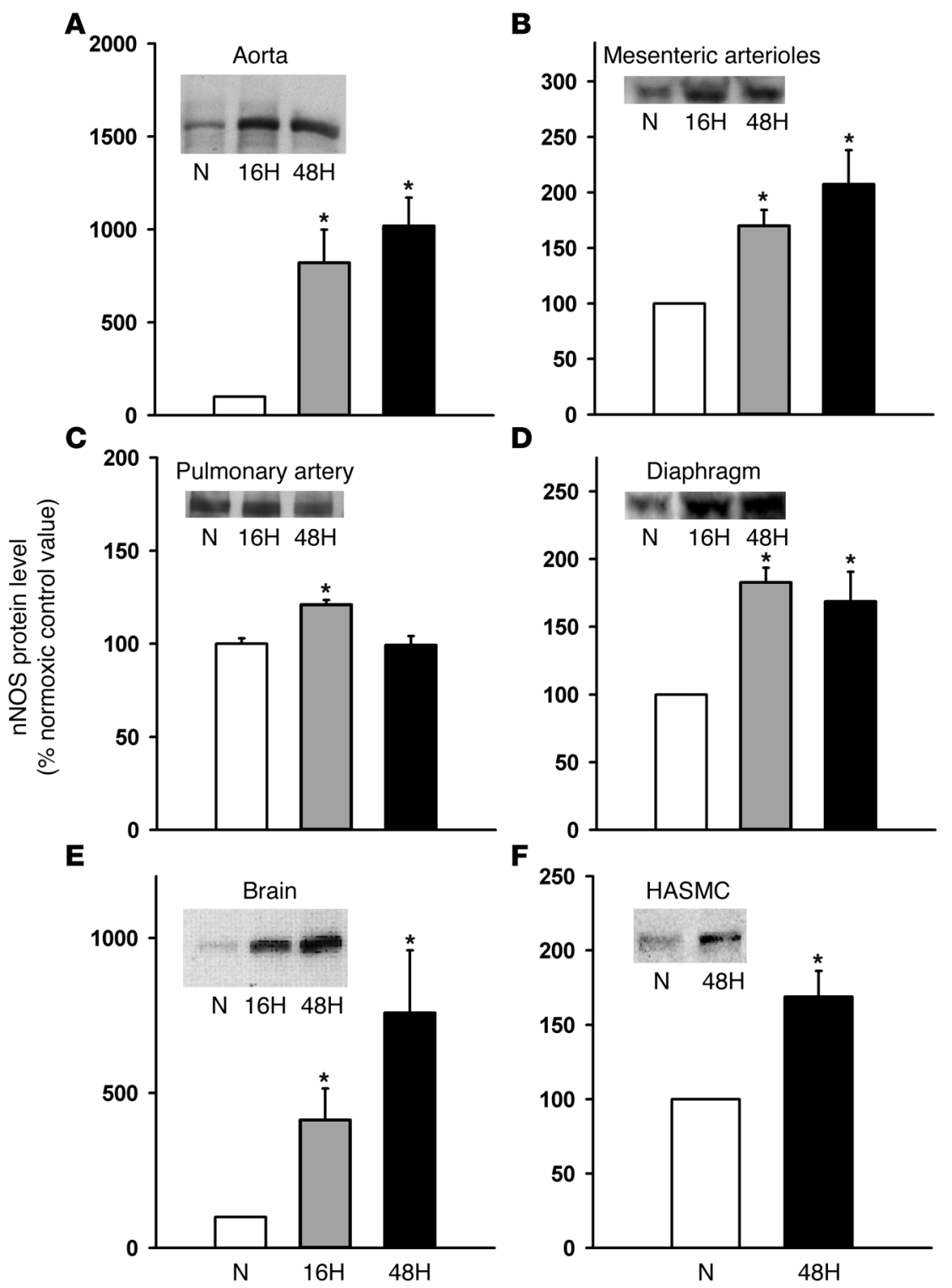

Figure 4

nNOS Western blots carried out on proteins from aortae (A; $n=5$ per group), mesenteric arterioles (B; $n=6$ per group), pulmonary arteries (C; $n=6$ per group), diaphragms (D; $n=6$ per group), and brains (E; $n=5$ per group) from normoxic rats (white bars, $\mathrm{N}$ ) and from rats exposed to hypoxia for 16 (gray bars, $16 \mathrm{H}$ ) and 48 (black bars, $48 \mathrm{H}$ ) hours and from HASMCs incubated under normoxic and hypoxic conditions for 48 hours $(F ; n=4$ per condition). ${ }^{*} P<0.05$ for difference from normoxic control value.

underscores that all 3 of the known mammalian NOS isoforms have been identified in vascular smooth muscle $(35,36)$.

Redistribution of blood flow so as to preferentially preserve vital organ oxygenation is a central component of the response to global hypoxia, and this requires that the vasculature be capable of responding to adjustments in adrenergic tone $(11,12)$. If restricted to the arterioles that regulate transvascular resistance, an increase in the capacity for NO production could be construed as part of an adaptive response, since it would result in inhibition of arteriolar tone most prominently in regions where the imbalance between oxygen delivery and metabolic demand is greatest. The loss of vascular contractility, although adaptive on a regional level, may have pathophysiologic significance in cardiopulmonary diseases associated with generalized impairment of systemic oxygen delivery. Previous studies indicate that after prolonged reductions in global oxygen delivery, impairment of systemic vasoreactivity is widespread, involving both resistance (13) and conductance vessels $(14,37)$. Our findings that hypoxia induced $n N O S$ expression in myocytes of conductance as well as in resistance vessels provides, in part, a newer molecular mechanism for these prior physiological observations.

Oxygen tension affects NO bioavailability at several levels. The enzymatic properties of the NOS isoforms are both dependent upon and regulated by oxygen. Molecular oxygen is a required substrate in the NOS reaction and, under hypoxic conditions, NO synthesis by iNOS becomes limited because of reduced substrate availability (38). In hyperoxic environments, reactive oxygen species combine with $\mathrm{NO}$, decreasing its availability for participation in vasoregulatory pathways (33). A more complex mechanism underlies oxygen regulation of NOS enzymatic activity over the physiological range of oxygen tensions, especially for nNOS. This level of control is enabled by the inhibitory interaction between self-generated $\mathrm{NO}$ and the ferrous heme center of the nNOS enzyme, the kinetics of which are determined by the availability of oxygen to compete for binding to this moiety (9). The cytotoxicity of NO is well documented $(7,39,40)$, and this autoinhibitory mechanism to limit NO production presumably plays an adaptive role in protecting susceptible tissues from exacerbation of ischemic injury.

Oxygen tension regulates the control of eNOS and NNOS mRNA expression, in major part, through transcriptional processes (41-43). In the current work, using the newer approach of insertional promoter/reporter transgenic mice, we have confirmed that hypoxia decreases transcriptional activity of the eNOS gene. Of great interest, we have shown that transcriptional activation of nNOS expression plays a major functional role in the impairment of systemic VSMC contractility after hypoxia. These results extend prior observations that nNOS expression is increased after hypoxic exposure in the lung (44) and the ventilatory muscles (19). Studies performed in vivo indicated that hypoxia led to the induction of endogenous nNOS mRNA transcripts, promoter/ $\beta$-galactosidase reporter RNA transcripts, and promoter/ $\beta$-galactosidase protein expression in vascular smooth muscle and a variety of other tissues and cell types, such as neurons and epithelial cells of the kidney. Together, these findings support an important role for induction of nNOS 

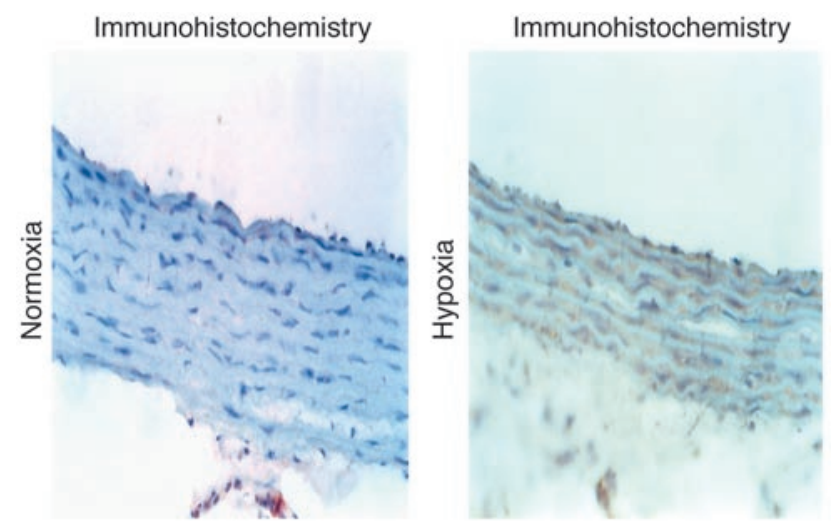

Figure 5

Immunohistochemistry for nNOS on aortic sections from normoxic rats and rats exposed to hypoxia for 48 hours.

expression in the ventilatory, metabolic, and vascular responses to systemic hypoxia and highlight the need for cell/tissue-specific mechanisms to overcome the intrinsically negative effect of hypoxia on NO production. Future studies will be required to define the functional importance of induction of renal epithelial and neuronal nNOS expression to integrated adaptive responses.

$n N O S$ mRNA expression is tightly regulated, consistent with its role in development (28) and in the adaptation to environmental stress $(45,46)$. This level of fine control is imposed, in part, through the cell- and tissue-specific production of differ- ent RNA transcripts (47). The molecular mechanisms by which this is achieved include site-specific alternate splicing $(25,28$, $29,48)$, cassette deletions/insertions $(22,49)$, and the use of alternate promoters $(23-25,50)$. The site of greatest diversity in nNOS mRNA structure is in the $5^{\prime}$-untranslated leader sequence. For the most part, this variability represents the expression of alternate first exons that splice to a common exon 2, where the translation initiation codon (AUG) is located. Ten distinct exon 1 variants have been identified in the human nNOS gene (Ex-1a, Ex-1b, and Ex-1c-j, based on their $5^{\prime}$ to $3^{\prime}$ order) $(23,29)$, each of which is accompanied by its own 5 '-flanking region and is assumed to be under the control of its own promoter that directs temporal- and tissue-specific expression. This concept has been confirmed experimentally for Ex-1c, Ex-1f, and Ex-1g (50-52). Genomic regions encoding these sequences possess functional promoter activity and are differentially regulated by transcription factor binding $(53,54)$. These promoters, which direct expression of $n N O S$ mRNAs abundant in neurons and skeletal muscle are clustered upstream of the ORF and include both TATA box-containing and TATA-less, GC-enriched promoter classes $(22,50)$.

Dynamic regulation of $n N O S$ mRNA transcripts is a newer area of study. Our current results indicate that hypoxia results in the transcriptional activation of the human $n N O S$ gene. Future studies will need to address the key cis-regulatory elements that control tissue nNOS activity during hypoxia. Because expression of the transgenic promoter/reporter construct used to create the insertional promoter/reporter mouse model in the present study recapitulated the expression of the native gene, sequences pres-

\section{Figure 6}

Effect of hypoxia on nNOS promoter/LacZ reporter transgenic mice. (A) General schema of the insertional exon 2 nNOS promoter/LacZ reporter transgene construct used to generate the transgenic mouse line. Representative histological sections are shown for $\beta$-galactosidase expression in renal papilla (Magnification: $\times 200$ ) and brain (Magnification: $\times 250)$ from $\mathrm{nNOS} / \mathrm{LaCZ}$ (B) and eNOS/LacZ reporter (C) mice exposed to normoxia or hypoxia; indicated magnifications are approximate.
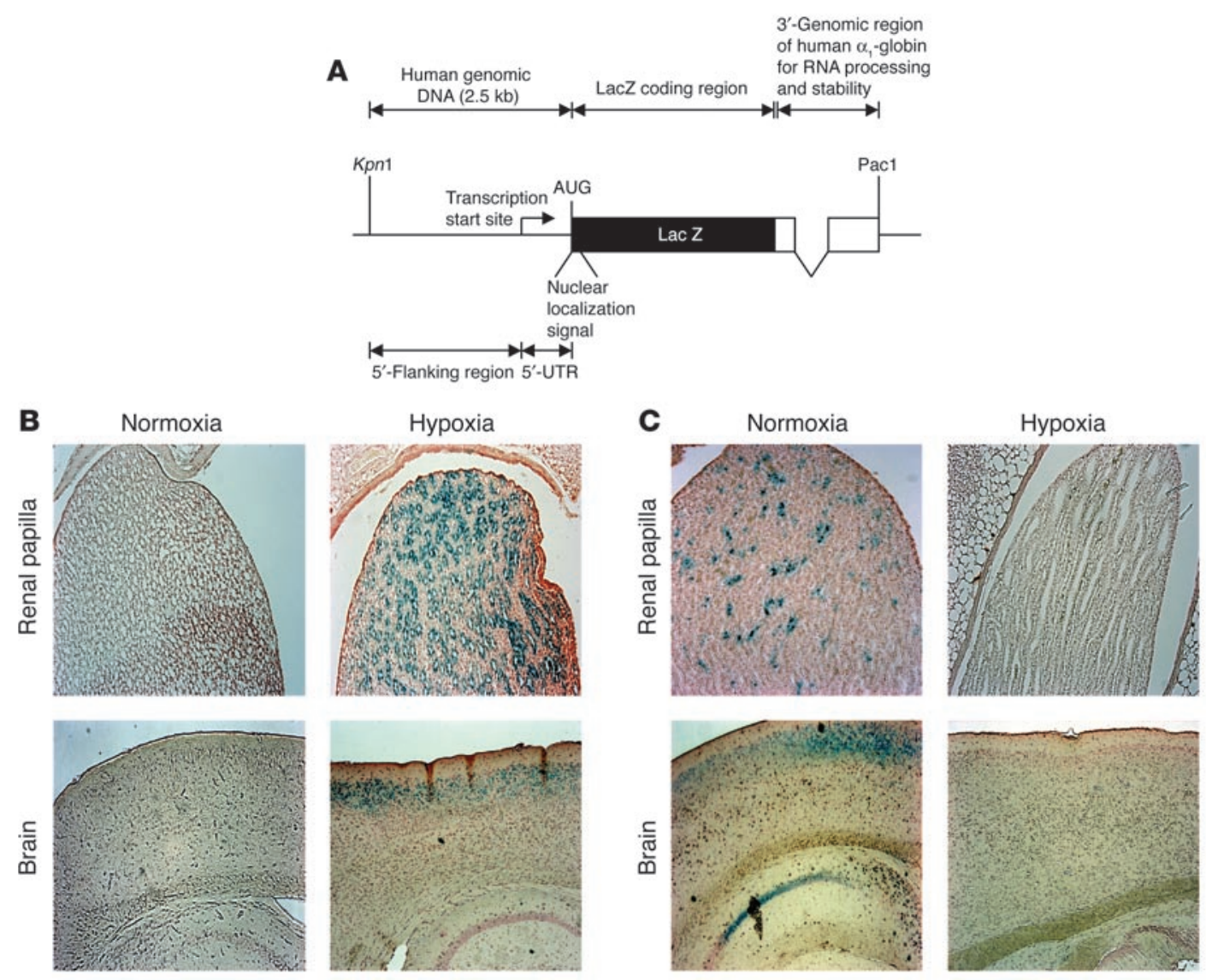

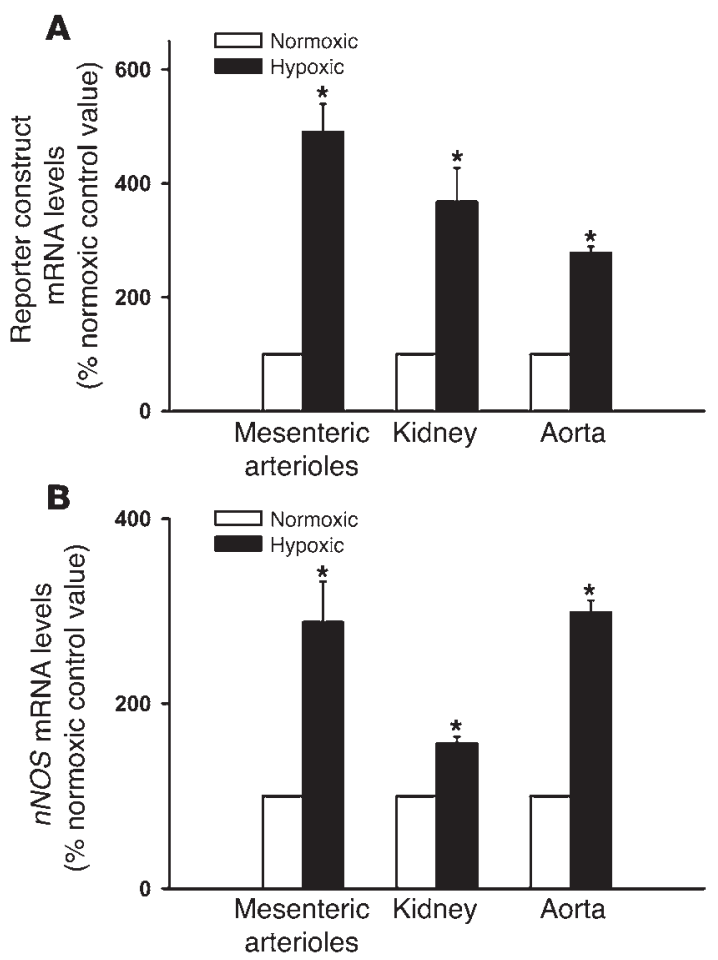

\section{Figure 7}

Effect of hypoxia (fraction of inspired oxygen $\left[\mathrm{FiO}_{2}\right]=0.8,48$ hours; gray bars) versus normoxia (white bars) on expression of the $n N O S / L a c Z$ reporter construct mRNA $(\mathbf{A})$ and native $n N O S$ mRNA $(\mathbf{B})$ in mesenteric arterioles, kidney, and aorta of eNOS/LacZ reporter transgene-positive mice.

ent on this construct (nt $-2,456$ to -77 ) are clearly relevant in the transcriptional response to hypoxia. In rodents Sasaki et al. (55) found evidence for $\mathrm{Ca}^{2+}$ influx-activated transcription in neurons. Characterization of mRNA species and in vitro functional assessment of promoter activity revealed 2 critical cAMP $/ \mathrm{Ca}^{2+}$ response elements (CREs) in orthologous genomic regions that correspond to the human sequences reported here. Activation of the genomic regions characterized here (GenBank accession number U17299), whether in vitro or in vivo, results in expression of mRNA transcripts with a short 5'-UTR representing sequences immediately upstream of the full-length ORF. TATAless and located within a CPG-depleted region of genomic DNA (nt composition of $-2,453$ to -77 with respect to the translation initiation codon is $49.6 \% \mathrm{G}$ or $\mathrm{C}$, with observed/expected ratio of CpG dinucleotides of 0.27 ; ref. 56), it is enriched for binding elements of ubiquitously expressed transcription factors including $\mathrm{CRE}$, activating protein-1 (AP-1), and the hypoxia-inducible factor-1 (HIF-1). CRE elements in promoter regions of the Bcl-2 and tyrosine hydroxylase genes mediate hypoxia-induced transcriptional activation, and hypoxia is associated with enhanced phosphorylation of the CREB transcription factor on serine 133 $(57,58)$. AP-1 also participates in hypoxic activation of tyrosine hydroxylase expression (59), as well as that of hemeoxygenase-1 (60). HIF-1, which regulates transcription of the gene encoding vascular endothelial growth factor, among others (61), binds specifically under hypoxic conditions to a $5^{\prime}$-RCGTG-3' hypoxiaresponsive element, found at $-3,099,-2,646,-1,185,-282,+275$, and +312 in the human $n N O S$ sequence. These sites are of particular interest in light of recent observations that inhibition of mitochondrial respiration by NO permits redirection of cellular oxygen to prolyl hydroxylases that regulate proteosomic degradation of HIF-1 $\alpha(62,63)$. Prolyl hydroxylase activity is limited by lack of $\mathrm{O}_{2}$ substrate during hypoxia, resulting in stabilization of HIF-1 $\alpha$ (64). Potentially, therefore, feedback autoinhibition of $n N O S$ expression may be affected at the transcriptional level through NO-dependent prolyl hydroxylase disinhibition and prevention of HIF- $1 \alpha$ stabilization.

The extreme size and complexity of the human $n N O S$ gene renders its transcription kinetically inefficient - requiring an estimated $1.6-2.5$ hours at $100-150 \mathrm{~kb} / \mathrm{h}(29,65)$. The hypoxia-responsive genomic regions of the human $n N O S$ gene are situated more than $100 \mathrm{~kb}$ downstream of the genomic regions that encode many of the constitutively expressed exon 1 variants. Moreover, the long and highly structured $n N O S 5^{\prime}$-UTRs evident in constitutively expressed $n N O S$ transcripts provide a translational impediment to efficient protein expression (23). In the current work, we confirmed that the long 5 -UTRs of $n N O S$ exon 1-containing mRNAs are poorly translated in both rabbit reticulocyte lysates and transfected cells. These RNA sequences do not have cap-independent IRES activity. This was an important concept to address, given that select mRNAs are preferentially translated during the cellular response to stress. For example, the translation of HIF-1 $\alpha$ continues efficiently when cells are exposed to hypoxia due to the presence of an IRES in the 5'-UTR (66). In general, most cellular mRNAs are inefficiently recruited to polysomes in the setting of hypoxia (67). Surprisingly, the translational efficiency of the nNOS mRNA species that is induced by hypoxia is itself not importantly inhibited by hypoxia. Therefore, the $n N O S$ gene represents a unique example of translational regulation in response to cellular hypoxia. In the case of human nNOS, hypoxia induces the transcriptional activation of a downstream promoter that produces mRNA species that are very efficiently translated compared with typical $n N O S$ mRNAs that are present under normoxic conditions.

In summary, $n N O S$ mRNA and protein expression are oxygen regulated at multiple levels, both transcriptional and translational. Our results highlight the previously unrecognized functional implications of nNOS in the regulation of vasomotor tone. The existence of such complex mechanisms to ensure that enzyme activity is specifically regulated in relation to tissue oxygenation speaks to the evolutionary and physiological importance of the adaptive response to hypoxia and the central role that nNOS plays in its implementation.

\section{Methods}

Functional studies. All protocols involving live animals were in accordance with standards set by the Canadian Council on Animal Care and were approved by the institutional animal care committees of Meakins-Christie Laboratories, the University of Toronto Faculty of Medicine, and St. Michael's Hospital. As described previously (14), male Sprague-Dawley rats (200-250 g; Charles River Laboratories) were placed in a Plexiglas chamber $(30 \times 18 \times 15 \mathrm{~cm})$ into which the flow of air and nitrogen was controlled independently for 48 hours, then sacrificed by decapitation. Animals exposed to hypoxia breathed a mixture containing $8 \%$ oxygen, whereas control animals breathed room air only under otherwise identical conditions.

In one set of experiments, thoracic aortae from normoxic rats and rats exposed to hypoxia were bisected, and one half of each aorta was denuded of its endothelium by gentle abrasion of the luminal surface before being 
A

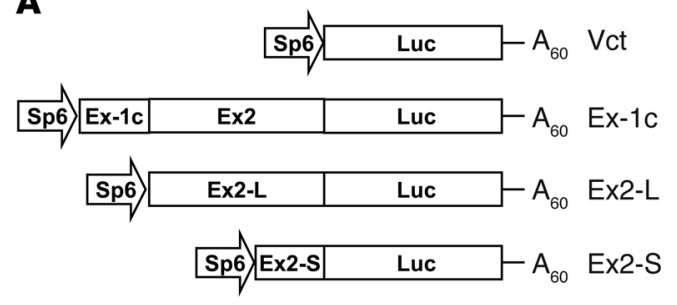

B

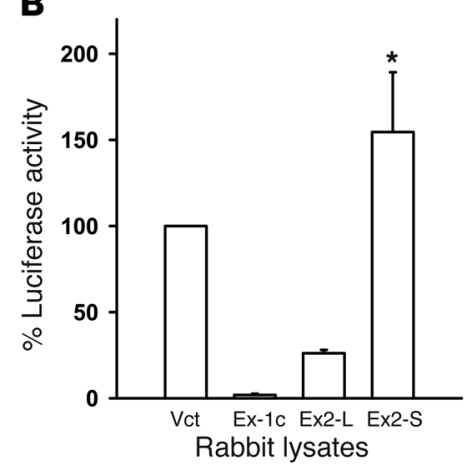

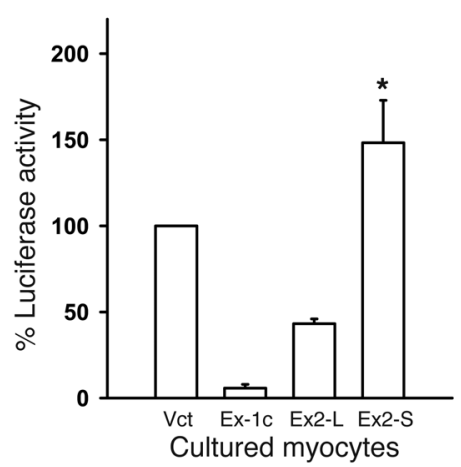

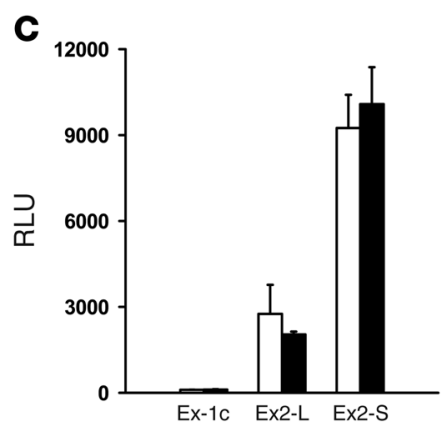

D
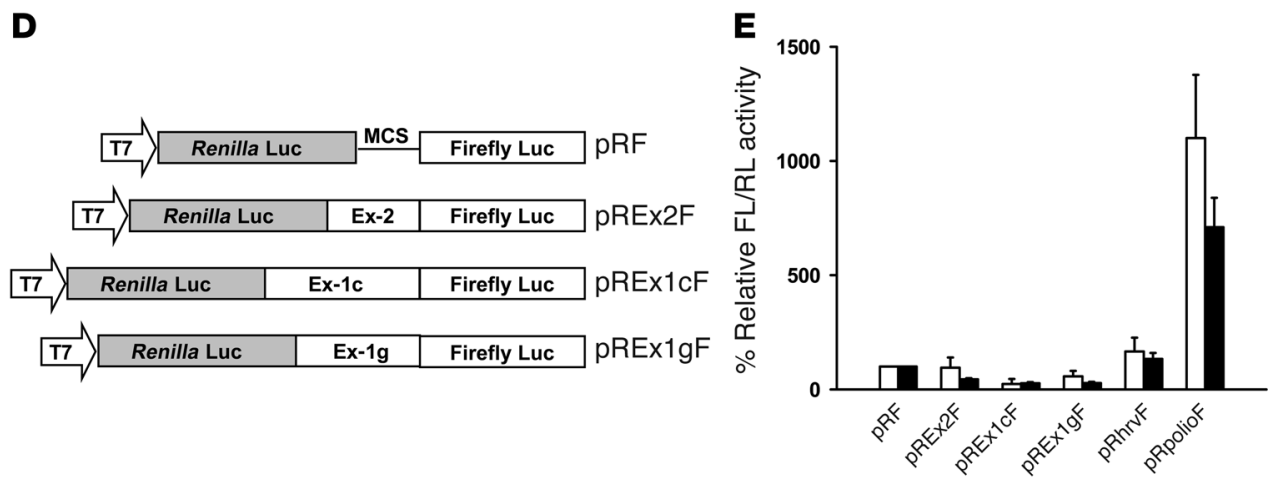

Figure 8

Effect of hypoxia on translation of nNOS leader exons. (A) Design of the monocistronic luciferase reporter constructs. Varied human $n N O S 5^{\prime}-U_{T R}$ sequences were placed upstream of the luciferase ORF. (B) Effect of the varied $n N O S$ leader sequences on the translational efficiency of reporter RNAs. In vitro-transcribed, capped, $n N O S 5^{\prime}$-UTR/luciferase reporter RNAs were transiently translated in rabbit reticulocyte lysates or transiently transfected into cultured $\mathrm{C} 2 \mathrm{C} 12$ myocytes. Data are expressed as the mean $\pm \mathrm{SEM}$ of 3 independent experiments, each performed in triplicate. ${ }^{*} P<0.05$ for difference from Ex2-Long (Ex2-L) value. Ex2-S, Ex2-Short; Vct, vector only. (C) Studies assessed the effect of normoxia (white bars) versus hypoxia ( 5 hours; black bars) on reporter Firefly luciferase activity in cultured myocytes (C2C12 cells) transiently transfected with RNA constructs containing the $n N O S$ Ex-1c, Ex2-Short, and Ex2-Long leader sequences. Shown is the mean \pm SEM of 3 independent experiments, each performed in triplicate. (D) Design of the bicistronic luciferase reporter constructs. Varied human $n N O S 5^{\prime}$-UTR sequences were inserted into the multiple cloning site (MCS) between the Renilla and Firefly luciferase ORFs. pRhrvF and pRpolioF containing the human rhinovirus IRES element and poliovirus IRES element, respectively, served as positive controls for IRES activity. (E) Ratio of Firefly to Renilla luciferase activity (FL/ $\mathrm{RL}$ ) relative to the activity of the control construct lacking any $n N O S 5^{\prime}$-UTR sequences (pRF) under normoxic (white bars) and hypoxic (5 hours; black bars) conditions. Studies assessed reporter activity in cultured myocytes (C2C12 cells) transiently transfected with bicistronic RNA constructs. Data are expressed as the mean \pm SEM of 3 independent experiments, each performed in triplicate.

sectioned into 4-mm rings. Segments were equilibrated in aerated KrebsHenseleit solution (in mmol/l: $120 \mathrm{NaCl}, 25 \mathrm{NaHCO}_{3}, 11.1$ glucose, 4.76 $\mathrm{KCl}, 1.18 \mathrm{MgSO}_{4}, 1.18 \mathrm{KH}_{2} \mathrm{PO}_{4}$, and $2.5 \mathrm{CaCl}_{2}$ ) for 1 hour at $37^{\circ} \mathrm{C}$ under a resting tension of $2 \mathrm{~g}$. The failure of acetylcholine (Ach; $10 \mu \mathrm{mol} / \mathrm{l}$ ) to elicit relaxation after contraction with PE $(1 \mu \mathrm{mol} / \mathrm{l})$ was taken as evidence of functional endothelial ablation. PE and Ach were then washed out, and the tension was allowed to return to $2 \mathrm{~g}$. Concentration-response relationships for $\mathrm{PE}(1 \mathrm{nmol} / \mathrm{l}$ to $10 \mu \mathrm{mol} / \mathrm{l})$ in endothelium-intact and -denuded rings or potassium chloride $(\mathrm{KCl} ; 0-50 \mathrm{mmol} / \mathrm{l})$ in endothelium-denuded rings were then generated in the presence and absence of L-NAME $(10 \mu \mathrm{mol} / \mathrm{l})$. At the end of each experiment, rings were dried overnight and weighed so that contraction could be expressed in $\mathrm{g} / \mathrm{mg}$ dry weight.

In a second series of experiments, resistance arterioles from the mesenteric circulation ( $100-200 \mu \mathrm{m}$ diameter) from normoxic rats and rats exposed to hypoxia were excised, and the endothelium was removed by gentle abrasion. Mesenteric arterioles were then cut into 2-mm segments and mounted in a wire myograph (purchased from University of Vermont) for measurement of isometric tension. A resting tension of $200 \mathrm{mg}$ was applied, and vessels were equilibrated in Krebs-Henseleit solution for 1 hour at $37^{\circ} \mathrm{C}$. Endothelial removal was verified by lack of a relaxation response to $1 \mu \mathrm{mol} / 1$
Ach after initial precontraction with PE $(1 \mu \mathrm{mol} / \mathrm{l})$. PE and Ach were then washed out, and the tension was allowed to return to $200 \mathrm{mg}$. Concentration-response relationships for PE $(10 \mathrm{nmol} / \mathrm{l}$ to $10 \mu \mathrm{mol} / \mathrm{l})$ were then constructed in the presence or absence of L-NAME $(10 \mu \mathrm{mol} / \mathrm{l})$.

Aortic NOS activity. Thoracic aortae from normoxic rats and rats exposed to hypoxia for 16 or 48 hours were excised and divided in half, and the endothelium was removed from one-half as described above. Aortae were homogenized in ice-cold $50 \mathrm{mmol} / 1$ Tris-buffered saline supplemented with $\operatorname{EDTA}(1 \mathrm{mmol} / \mathrm{l})$ and EGTA ( $1 \mathrm{mmol} / \mathrm{l})$. Samples were centrifuged at $14,000 \mathrm{~g}$, and the protein content in the supernatants was quantified by the Bradford method (Bio-Rad Laboratories). NOS activity in the presence and absence of $\mathrm{CaCl}_{2}(0.6 \mathrm{mmol} / \mathrm{l})$ was measured using the NOSdetect Assay Kit from Stratagene. Briefly, 50-100 $\mu \mathrm{g}$ of homogenate $(10 \mu \mathrm{l})$ was added to a reaction mixture consisting of Tris- $\mathrm{HCl}(25 \mathrm{mmol} / \mathrm{l}, \mathrm{pH} 7.4), \mathrm{BH}_{4}$ ( $3 \mu \mathrm{mol} / \mathrm{l})$, flavin adenine dinucleotide $(1 \mu \mathrm{mol} / \mathrm{l})$, flavin mononucleotide $(1 \mu \mathrm{mol} / \mathrm{l}), \mathrm{NADPH}(1 \mathrm{mmol} / \mathrm{l}),\left[{ }^{3} \mathrm{H}\right]$-L-arginine $(0.2 \mu \mathrm{Ci} / \mu \mathrm{l}$; Amersham Biosciences) and calmodulin $(0.1 \mu \mathrm{mol} / \mathrm{l})$. After a 1-hour incubation at $37^{\circ} \mathrm{C}$, the reaction was terminated with HEPES buffer $(50 \mathrm{mmol} / \mathrm{l}, \mathrm{pH} 5.5)$ containing EDTA $(5 \mathrm{mmol} / \mathrm{l})$. The mixture was filtered through a Dowex resin, and the radioactivity corresponding to $\left[{ }^{3} \mathrm{H}\right]$-L-citrulline was mea- 
sured in $100 \mu \mathrm{l}$ of the eluate by liquid scintillation. For each sample, $\left[{ }^{3} \mathrm{H}\right]$-L-citrulline production was also assayed in the presence of L-NAME $(1 \mathrm{mmol} / \mathrm{l})$. This value was used as a control to subtract all non-NOS-derived L-arginine conversion present. In all experiments, triplicate measurements for each sample were averaged and treated as a single observation.

Western blotting. Thoracic aortae, mesenteric arterioles, first-order pulmonary arteries, diaphragms, and brains were excised from normoxic rats and from rats exposed to hypoxia for 48 hours, and proteins were extracted in $1 \% \mathrm{SDS}, 1 \mathrm{mmol} / \mathrm{l} \mathrm{Na}_{3} \mathrm{VO}_{4}$ and $10 \mathrm{mmol} / \mathrm{l}$ Tris ( $\mathrm{pH}$ 7.4) with a proteinase inhibitor cocktail (Sigma-Aldrich). To confirm that human nNOS expression was also oxygen regulated and to address the direct effect of hypoxia in vitro, nNOS protein levels were measured in HASMCs after normoxic and hypoxic incubation. HASMCs were from Clonetics and maintained as described (68). At passage 6, upon reaching $80 \%$ confluence, the cells were exposed to either a hypoxic $\left(1 \% \mathrm{O}_{2}, 5 \% \mathrm{CO}_{2}, 94 \% \mathrm{~N}_{2}\right)$ or normoxic $\left(21 \% \mathrm{O}_{2}\right.$, $5 \% \mathrm{CO}_{2}, 74 \% \mathrm{~N}_{2}$ ) gas mixture for 48 hours. Proteins were extracted in extraction buffer as described above and quantified by the Bradford method.

Proteins from thoracic aortae, mesenteric arterioles, pulmonary arteries, diaphragms, and brains from normoxic and hypoxia-exposed rats and from HASMCS were separated on a 4-12\% SDS-polyacrylamide gel, transferred onto nitrocellulose or PVDF, and probed with an nNOS-specific monoclonal or polyclonal antibody (BD Biosciences). Aortic proteins from normoxic and hypoxia-exposed rats were also incubated with iNOSspecific monoclonal antibody (BD Biosciences - Transduction Laboratories). Immunoblots were probed with HRP-linked donkey anti-rabbit IgG (Amersham Biosciences) or HRP-linked goat anti-mouse IgG (SigmaAldrich). Immunoreactive bands were detected by enhanced chemiluminescence (Amersham Biosciences) and quantified by densitometry using a Hewlett-Packard scanner and Molecular Analyst software (Bio-Rad Laboratories). Protein loading and transfer efficiency were verified by full-lane densitometry of the Ponceau red-stained membranes.

Immunohistochemistry. Thoracic aortae from rats exposed to normoxia or hypoxia for 48 hours were fixed in $4 \%$ paraformaldehyde and embedded in paraffin. Sections were analyzed by indirect immunohistochemistry using a polyclonal antibody to an epitope in the carboxyl terminus of the nNOS protein (BD Biosciences - Transduction Laboratories) and an HRP-labeled anti-rabbit secondary antibody (Amersham Biosciences). Diaminobenzidine was used as the substrate for HRP, and tissues were counterstained with H\&E. Slides processed in an identical manner, except omitting the primary antibody served as negative controls.

In situ hybridization. Aortae from rats exposed normoxia or hypoxia for 48 hours were fixed in $4 \%$ paraformaldehyde and sectioned. In situ hybridization was carried out on these tissue sections as previously described (16, 68 ) using an $\left.{ }^{35} \mathrm{~S}\right]$-labeled antisense riboprobe complementary to exon 2 of the full-length $n N O S$ mRNA (GenBank accession number NM 052799). Tissue sections were permeabilized with Triton X-100 and proteinase $\mathrm{K}$ and treated with acetic anhydride and triethanolamine and with a further solution of $\mathrm{N}$-ethylmaleimide and iodoacetamide. Tissue sections were then incubated overnight with the radiolabeled probe at $42^{\circ} \mathrm{C}$, treated with RNase A, washed with $\times 2$ to $\times 0.1$ saline sodium citrate at $22^{\circ} \mathrm{C}$ to $55^{\circ} \mathrm{C}$, and then processed for autoradiography. $\left[{ }^{35} \mathrm{~S}\right]$-labeled sense riboprobe was used as a negative control.

Rapid amplification of cDNA ends (5'-RACE). We sought to characterize the mRNA transcript(s) whose expression is stimulated by hypoxia by identifying those enriched in HASMCs after 48 hours of hypoxic incubation compared with cells cultured under normoxic conditions (see above) using the method of 5'-RACE. The gene-specific primer was located in the exon 2 coding region, thus allowing the isolation of human $n N O S$ CDNA sequences upstream of exon 2. Total cellular RNA $(1 \mu \mathrm{g})$ derived from HASMCs incubated under normoxic and hypoxic conditions for 48 hours was reverse transcribed with gene-specific antisense primer P1 (exon 2, 5'-CCATGGTAACTAGCTTCC-3') using SuperScript II reverse transcriptase (Life Technologies; Invitrogen Corp.). RNase $\mathrm{H}$ was used to remove template RNA, and first-strand cDNA product was tailed with dATP by terminal deoxynucleotide transferase, as described previously (24). First-round PCR was performed for 35 cycles with primer annealing at $55^{\circ} \mathrm{C}$ (generic sense primers 5'-GACTCGAGTCGACGAATTCAAT-3', 2.5 pmol, and 5'-GACTCGAGTCGACGAATTCAA-3', 25 pmol; gene-specific anti-sense primer P2, exon 2, $5^{\prime}$-TCTCTAAGGAAGTGATGGTTG-3', 25 pmol). A second round of amplification was performed for 35 cycles with primer annealing at $57^{\circ} \mathrm{C}$ (generic sense primer 5'-GACTCGAGTCGACGAATTCAA-3', 25 pmol; nested genespecific antisense primer P3, exon 2, 5'-GGCTGTGTCTAGAAGTGACG-3', $25 \mathrm{pmol})$. PCR products were digested with EcoRI/XbaI, subcloned into pBluescript SK(-), and subjected to DNA sequence analysis. An independent series of 5'-RACE was also performed with primers located downstream of the described primer set using a similar approach (exon 2, 5'-GTACCTCCAGGGCGCTGT- ${ }^{\prime}$ and $5^{\prime}$-CCATGGTAACTAGCTTCC- $3^{\prime}$ ).

Genomic characterization. P1 clones were isolated by PCR-based screening from a library of human diploid genomic DNA partially digested with Sau3AI in the vector pAD10SacBII (Genome Systems). Two pairs of genomic PCR primers were used for screening (primer pair 1, Ex-1f sense: $5^{\prime}$-CCTGCGTGGCTACTACATTC-3', Ex-1f antisense: 5'-AGACGTCGCAACCCTCATTA3'; primer pair 2, Ex-1c sense: 5'-GACTGCCTGACTGCCCTTGT-3', Ex-1c antisense: $5^{\prime}$-CCCCCTCTCAGACAGTGCTC-3'). Three overlapping P1 clones were mapped with the method of partial enzymatic digestion using EcoRI, MluI, SalI, and SmaI on a CHEF-DR III mapping system (Bio-Rad Laboratories). Southern blots were hybridized with $\left[\gamma_{-}{ }^{32} \mathrm{P}\right]$ ATP-labeled T7 and $\mathrm{Sp} 6$ primers and primers specific for exon 2. High-molecular-weight P1 DNA was partially digested with Sau3AI, subcloned into the BamHI site of pBluescript SK(-), and subjected to DNA sequence analysis. Genomic DNA sequence was determined on both strands of genomic DNA with an ABI PRISM 377 automated DNA sequencer (Applied Biosystems).

$n N O S / L a c Z$-transgenic mouse. The nNOS/LacZ-transgenic mouse line was generated in a hybrid C57BL6/SJL mouse strain, through the National Institute of Child Health and Human Development Transgenic Mouse Development Facility, University of Alabama, using techniques described previously $(20,69)$. These mice expressed the E. coli LacZ ( $\beta$-galactosidase) reporter gene under the transcriptional control of human $n N O S$ genomic regions spanning $-2,453$ to -77 numbered with respect to the start site of translation (GenBank accession number U17299; Figure 6A). This genomic region contains $418 \mathrm{nt}$ of sequence included in the 5 '-UTRs of previously described human $n N O S$ cDNAs that corresponds to exon 2 regions of cDNAs known to contain various exon 1 leader sequences (23). The LacZ ( $\beta$-galactosidase) reporter gene contained the SV40 large T nuclear localization signal (5'-GGGCCCAAGAAGAAACGCAAAGTGGGGAG-3') and a eukaryotic translation initiation signal. A 516-bp HindIII fragment representing the 3 '-UTR and 3 '-flanking genomic regions of the human $\alpha_{1}$-globin gene was incorporated at the 3 '-end of the LacZ ORF to ensure proper RNA processing $(20,69)$. Tail genomic DNA was isolated at the time of weaning, and genotyping was performed by a modified Southern slot blot, as described previously (69). From 8 original $\mathrm{F}_{0}$ founders, 5 founder lines transmitted the transgene to the $\mathrm{F}_{1}$ progeny and exhibited normal Mendelian heritability. The $n N O S$ exon 2 promoter/LacZ reporter-transgenic mouse line and a previously established and characterized murine eNOS promoter/LacZ reporter-transgenic mouse line (69) were used and characterized in the current study. Both transgenic mouse lines were exposed to either normobaric hypoxia $\left(\mathrm{FiO}_{2}=0.08\right)$ or normoxia for 48 hours and then euthanized with ketamine/xylazine (200 and $10 \mathrm{mg} / \mathrm{kg}$, respectively, intraperitoneally). Heart, lungs, kidneys, brain, and aorta were excised, sectioned $(0.25-\mathrm{cm}$ sections), and placed in a fixative buffer ( $2 \%$ formalin, 
$0.2 \%$ glutaraldehyde, $5 \mathrm{mmol} / \mathrm{l} \mathrm{EGTA}, 2 \mathrm{mmol} / 1 \mathrm{MgCl}_{2}, 0.1 \mathrm{~mol} / \mathrm{l}$ sodium phosphate buffer; $\mathrm{pH} 7.3$ ) for 4-6 hours. Fixed tissues were embedded in paraffin, cut into $10-\mu \mathrm{m}$ sections, stained for $\beta$-galactosidase, and counterstained with nuclear red, as described previously (69). Slides were visualized using a Leica model DM RBE upright microscope (Leica Microsystems Canada Inc.), and images were captured using a CoolSnap camera and the accompanying software (version 1.2.0; Roper Scientific Inc.).

Real-time RT-PCR. All quantitative PCR analysis was performed using an ABI PRISM 7900 HT (Applied Biosystems) using the SYBR Green detection system. The quality of total cellular RNA was assessed using the Agilent 2100 Bioanalyzer (Agilent Technologies). First-strand cDNA was synthesized with total cellular RNA $(1-5 \mu \mathrm{g})$ derived from varied murine tissues (kidney, aorta, and mesenteric blood vessels) using random primers and SuperScript II reverse transcriptase (Life Technologies; Invitrogen Corp.). Reactions were performed in triplicate on pools of cDNA synthesized from experiments performed in 3 independent founder lines containing the cDNA equivalent of $100 \mathrm{ng}$ of reverse-transcribed RNA. To quantitate copy number, we used serial 10-fold dilutions of plasmids corresponding to target RNAs to generate standard curves. For quantitation of $n N O S$ in murine tissues, primers spanned a common region (exon 8/9): murine $n N O S$ sense $5^{\prime}$-TGGGCGATCCAGCTAATGTGG-3', murine $n N O S$ antisense $5^{\prime}$ GGGGATCTGAAAGAGTTCAGGGTC-3'. For quantification of reporter RNAs in murine $n N O S$ promoter $\beta$-galactosidase (LacZ) reporter mice, the real-time primer pair crossed an intron located within the human $\alpha_{1}$-globin $3^{\prime}$-UTR and flanking genomic sequences used for primary transcript processing: reporter $L a c Z / \alpha$-globin sense 5 '-ACCCGGTCAACTTCAAGCTCC$3^{\prime}$, reporter Lac $Z / \alpha$-globin antisense 5 '-GGTGCTCACAGAAGCCAGGAA$3^{\prime}$. The following housekeeping genes and primers were employed: murine Gapdh sense 5'-TTCACCACCATGGAGAAGG-3'; murine Gapdh antisense 5'-CTCGTGGTTCACACCCATC-3'; 18S sense 5'-AGGAATTGACGGAAGGGCAC'-3'; 18S antisense 5'-GGACATCTAAGGGCATCACA-3'; murine Hprt sense 5'-AAACAATGCAAACTTTGCTTTCC-3'; murine Hprt antisense 5'-AGCTTGCTGGTGAAAAGGACC-3'.

Generation of reporter constructs. Translation assays were carried out using RNA rather than DNA transfections in order to eliminate factors related to transcriptional regulation. A series of in vitro RNA expression vectors was constructed using a modified pSP-Luc ${ }^{+}$plasmid (Promega) that included a sequence of 60 adenylate residues $3^{\prime}$ of the luciferase ORF, as previously described $(23,29)$. The luciferase protein coded by the ORF was identical in all constructs to obviate differences resulting from differences in protein stability. The complete 5 '-UTR portion of exon 2 from the human $n N O S$ was placed upstream of the luciferase ORF. This construct, termed Ex2-Long, possessed a 5'-UTR of 405 nt. The Ex2-Long construct was truncated via the native Bam HI site to generate the Ex2-Short reporter construct, which then contained $77 \mathrm{nt}$ of 5'-UTR sequence. For comparative purposes, a previously described (29) Ex-1c-containing reporter was included. This construct contained $326 \mathrm{nt}$ of Ex-1c sequence (GenBank accession number AF049714) followed by the complete $5^{\prime}$-UTR portion of exon 2 , thereby possessing $831 \mathrm{nt}$ of $5^{\prime}$-UTR sequence. In previous studies and the current work, the stability of these mRNA constructs was found to be unaltered by varying the 5 -UTR sequence $(23,29)$.

To assess the possible presence of an IRES (70) in the $5^{\prime}$-UTR of the hypoxia-inducible human $n N O S$ mRNA, bicistronic plasmids were generated to compare the translational efficiency of a transcript containing this sequence or $n N O S$ exon $15^{\prime}$-UTRs with that of an mRNA containing the well-characterized polio virus IRES (71). The plasmids pRF and pRhrvF, which contains a human rhinovirus IRES, were kind gifts from A. Willis (University of Leicester, Leicester, United Kingdom) and have been previously described (72). To create the bicistronic plasmids pREx2F, pREx1cF, and $\mathrm{pREx} 1 \mathrm{gF}, n N O S \mathrm{CDNA}$ sequences containing the untranslated region of exon 2 and the Ex-1c or Ex-1g variant were inserted into the multiple cloning site of the pRF vector. To create the pRpolioF construct, cDNA encoding the polio virus IRES element (a kind gift from J. Pelletier, McGill University) was inserted into the pRF vector.

RNA transfections. C2C12 cells [mouse skeletal myoblast, nNOS(+); ATCC] were grown in DMEM supplemented with $15 \%$ FBS and antibiotics. PC12 cells [rat pheochromocytoma, nNOS(+); ATCC] were maintained in RPMI supplemented with $10 \%$ heat-inactivated horse serum, $5 \%$ FBS, and antibiotics (Gibco; Invitrogen Corp.). CHO-K1 cells [nNOS(+); ATCC] were grown in DMEM supplemented with $10 \%$ FBS and antibiotics. In vitro transcription of capped RNA was carried out using the Sp6 and T7 mMessageMachine kit (Ambion Inc.). The quality of in vitro-synthesized, $7 \mathrm{mGpppG}$-capped RNA was assessed on $0.66 \mathrm{M}$ formaldehyde- $1 \%$ agarose gels. Cells were maintained in $60-\mathrm{mm}$ dishes and transfected at $50-70 \%$ confluency with in vitro-synthesized, quantified, capped RNA using Lipofectin (Life Technologies; Invitrogen Corp.). Three or $5 \mu \mathrm{g}$ of RNA and $12 \mu \mathrm{l}$ of Lipofectin (Life Technologies; Invitrogen Corp.) were used for each 60$\mathrm{mm}$ dish along with $2 \mu \mathrm{g}$ of respiratory syncytial virus- $\beta$-galactosidase RNA or $0.3 \mu \mathrm{g}$ of Renilla luciferase RNA to control for transfection efficiency. Cellular extract was harvested 4-6 hours after RNA transfection, at which time reporter activity was increasing linearly as a function of time $(23,29)$. Multiple independent RNA preparations were used. Luciferase activity was measured with a luminometer (Monolight 2010C; Analytical Luminescence Laboratory) and normalized for $\beta$-galactosidase activity and protein content, as described previously $(23,29)$. For anaerobic transfections, cells were incubated under normoxic conditions for 1 hour then transferred to an anaerobic $\left(<1 \% \mathrm{O}_{2}\right)$ chamber for 5 hours prior to harvesting in $\times 1$ passive lysis buffer (Promega). The dual luciferase assay kit (Promega) was used to determine the amounts of Firefly and Renilla luciferase activities in transfected cells using a plate luminometer (Microplate Luminometer LB 96V; EG\&G Berthold). Firefly luciferase was normalized to Renilla luciferase activity. In vitro translations were performed in rabbit reticulocyte lysates (Promega), as described previously (23).

Statistics. Unless otherwise stated, experiments were performed at least 3 times. Results of functional studies in aortic and arteriolar segments studied under a given condition from a given animal were averaged and the averaged value used as a single data point in the statistical analysis. Paired means were compared by 2 -tailed Student's $t$ test. Differences among multiple means were evaluated by ANOVA corrected for multiple measures where appropriate, and, when overall differences were detected, individual means were compared post hoc using the Student-Neuman-Keuls procedure. Results are presented as mean \pm SEM for $n$ number of samples, with $P<0.05$ representing statistical significance.

\section{Acknowledgments}

This study was funded by a grant from the Canadian Institutes of Health Research (128316). The authors thank Patrice Vaillancourt for his expert technical assistance. P.A. Marsden is the recipient of a Career Investigator Award from the Heart and Stroke Foundation and is supported by a grant from the Heart and Stroke Foundation of Canada (T-4632).

Received for publication December 15, 2003, and accepted in revised form August 30, 2005.

Address correspondence to: Michael E. Ward, Department of Critical Care, St Michael's Hospital, Rm 4-015 Bond Wing, 30 Bond Street, Toronto, Ontario M5B 1W8, Canada. Phone: (416) 864-6060 ext. 4140; Fax: (416) 864-5349; E-mail: wardm@smh. toronto.on.ca. 
1. Boulanger, C.M., Heymes, C., Benessiano, J., and Geske, R.S. 1998. Neuronal nitric oxide synthase is expressed in rat vascular smooth muscle cells: activation by angiotenisin II in hypertension. Circ. Res. 83:1271-1278.

2. Nathan, C., and Xie, Q.-W. 1994. Nitric oxide synthases: roles, tolls and controls. Cell. 78:915-918.

3. Cervenka, L., et al. 2002. Role of nNOS in regulation of renal function in hypertensive Ren-2 transgenic rats. Physiol. Res. 51:571-580.

4. Gautier, H., and Murariu, C. 1999. Role of nitric oxide in hypoxic hypometabolism in rats. J. Appl. Physiol. 87:104-109.

5. Steiner, A.A., Carnio, E.C., and Branco, L.G.S 2000. Role of neuronal nitric oxide synthase in hypoxia-induced anapyrexia in rats. J. Appl. Physiol. 89:1131-1136.

6. Kline, D.D., Yang, T., Huang P.L., and Prabhakar, N.R. 1998. Altered respiratory responses to hypoxia in mutant mice deficient in neuronal nitric oxide synthase. J. Physiol. 15:273-287.

7. Yuyama, K., et al. 2003. Caspase-independent cell death by low concentrations of nitric oxide in $\mathrm{PC} 12$ cells: involvement of cytochrome $\mathrm{C}$ oxidase inhibition and the production of reactive oxygen species in mitochondria. J. Neurosci. Res. 73:351-363.

8. Huang, Z., et al. 1994. Effects of cerebral ischemia in mice deficient in neuronal nitric oxide synthase. Science. 265:1883-1885.

9. Abu-Soud, H.M., Rousseau, D.L., and Stuehr, D.J. 1996. Nitric oxide binding to the heme of neuronal nitric-oxide synthase links its activity to changes in oxygen tension. J. Biol. Chem. 271:32515-32518.

10. Prabhakar, N.R., Pieramici, S.F., Premkumar, D.R., Kumar, G.K., and Kalaria, R.N. 1996. Activation of nitric oxide synthase gene expression by hypoxia in central and peripheral neurons. Brain Res. Mol. Brain Res. 43:341-346.

11. Cain, S.M., and Chapler, C.K. $1980 . \mathrm{O}_{2}$ extraction by canine hindlimb during alpha-adrenergic blockade and hypoxic hypoxia. J. Appl. Physiol. 48:630-635.

12. Doherty, J.U., and Liang, S.-S. 1984. Arterial hypoxia in awake dogs: role of the sympathetic nervous system in mediating the systemic hemodynamic and regional blood flow responses. J. Lab. Clin. Med. 104:665-667

13. Toporsian, M.T., and Ward, M.E. 1997. Hyporeactivity of rat diaphragmatic arterioles following exposure to hypoxia in vivo: role of the endothelium. Am. J. Respir. Crit. Care Med. 156:1572-1578.

14. Auer, G., and Ward, M.E. 1998. Impaired reactivity of rat aorta to phenylephrine and $\mathrm{KDCl}$ after prolonged hypoxia: role of the endothelium. J. Appl. Physiol. 85:411-417.

15. Heistad, D.D., Wheeler, R.C., and Aoki, V.S. 1971 Reflex cardiovascular responses after $36 \mathrm{hr}$ of hypoxia. Am. J. Physiol. 220:1673-1676

16. Wilcox, J.N., et al. 1997. Expression of multiple isoforms of nitric oxide synthase in normal and atherosclerotic vessels. Arterioscler. Thromb. Vasc Biol. 17:2479-2488.

17. Papadaki, M., Tilton, R.G., Eskin, S.G., and McIntire, L.V. 1998. Nitric oxide production by cultured human aortic smooth muscle cells: stimulation by fluid flow. Am. J. Physiol. Heart Circ. Physiol. 43:H616-H626.

18. Schwarz, P.M., Kleinert, H., and Forstermann, U. 1999. Potential functional significance of brain-type and muscle-type nitric oxide synthase I expressed in adventitia and media of rat aorta. Arterioscler. Thormb. Vasc. Biol. 19:2584-2590.

19. Javeshghani, D., Sakkal, D., Mori, M., and Hussain, S.N.A. 2000. Regulation of diaphragmatic nitric oxide synthase expression during hypobaric hypoxia. Am. J. Physiol. Lung Cell Mol. Physiol. 279:L520-L527.

20. Wang, Y., et al. 2002. An alternative promoter of the human neuronal nitric oxide synthase gene is expressed specifically in Leydig cells. Am. J. Pathol. 160:369-380

21. Young, A.P., Murad, F., Vessin, H., Xie, J., and Rife, T.K. 1995. Transcription of the human neuronal nitric oxide synthase gene in the central nervous system is mediated by multiple promoters. $A d v$. Pharmacol. 34:91-112.

22. Hall, A.V., et al. 1994. Structural organization of the human neuronal nitric oxide synthase gene (NOS 1). J. Biol. Chem. 269:33082-33090.

23. Wang, Y., et al. 1999. RNA diversity has profound effects on the translation of neuronal nitric oxide synthase. Proc. Natl. Acad. Sci. U. S. A. 96:12150-12155

24. Wang, Y., Goligorsky, M.S., Lin, M., Wilcox, J.N., and Marsden, P.A. 1997. A novel, testis-specific mRNA transcript encoding an NH2-terminal truncated nitric-oxide synthase. J. Biol. Chem. 272:11392-11401.

25. Saur, D., Paehge, H., Schusdziarra, B., and Allescher, H.-D. 2000. Distinct expression of splice variants of neuronal nitric oxide synthase in the human gastrointestinal tract. Gastroenterology. 118:849-858.

26. Wang, Y., et al. 2002. An alternative promoter of the human neuronal nitric oxide synthase gene is expressed specifically in Leydig cells. Am. J. Pathol. 160:369-380.

27. Zacour, M.E., Toporsian, M., Auer, G., Cernacek, P., and Ward, M.E. 1999. Local release of endothelin enhances aortic contractility following prolonged hypoxia in-vivo. Pulm. Pharmacol. Ther. 11:197-199.

28. Lee, M.A., Cai, L., Hubner, N., Lee, Y.A., and Lindpaintner, K. 1997. Tissue- and development-specific expression of multiple alternatively spliced transcripts of rat neuronal nitric oxide synthase. J. Clin. Invest. 100:1507-1512.

29. Newton, D.C., et al. 2003. Translational regulation of human neuronal nitric-oxide synthase by an alternatively spliced $5^{\prime}$-untranslated region leader exon. J. Biol. Chem. 278:636-644.

30. Stoneley, M., and Willis, A.E. 2004. Cellular internal ribosome entry segments: structures, transacting factors and regulation of gene expression. Oncogene. 23:3200-3207.

31. Earley, S., and Walker, B.R. 2003. Increased nitric oxide production following chronic hypoxia contributes to attenuated systemic vasoconstriction. Am. J. Physiol. Heart Circ. Physiol. 284:H1655-H1661.

32. Papadaki, M., Tilton, R.G., Eskin, S.G., and McIntire, L.V. 1998. Nitric oxide production by cultured human aortic smooth muscle cells: stimulation by fluid flow. Am. J. Physiol. Heart Circ. Physiol. 274:H616-H626

33. Rosenfeld, C.R., Chen, C., Roy, T., and Liu, X.-T. 2003. Estrogen selectively up-regulates eNOS and nNOS in reproductive arteries by transcriptional mechanisms. J. Soc. Gynecol. Investig. 10:205-215.

34. Tsutsui, M. 2004. Neuronal nitric oxide synthase as a novel anti-atherogenic factor. J. Atheroscler Thromb. 11:41-48.

35. Gaudino, M., Toesca, A., Maggiano, N., Pragliola, C, and Possati, G. 2003. Localization of nitric oxide synthase type III in the internal thoracic and radial arteries and the great saphenous vein: a comparative immunohistochemical study. J. Thorac. Cardiovasc. Surg. 125:1510-1515.

36. Yoshida, M., Nakanishi, N., Wang, X., and Hattori, Y. 2003. Exogenous biopterins requirement for iNOS function in vascular smooth muscle cells. J. Cardiovasc. Pharmacol. 42:197-203.

37. Toporsian, M.T., et al. 2000. Downregulation of endothelial nitric oxide synthase (NOS III) in rat aorta following in-vivo hypoxia. Circ. Res. 86:671-675.

38. Nagao, K., Takenaka, S., Yamaji, R., Inui, H., and Nakano, Y. 2003. Nitric oxide synthase induction, cGMP elevation, and biopterin synthesis in vascular smooth muscle cells stimulated with interleu- kin-1 beta in hypoxia. J. Biochem. 133:501-505.

39. Quast, M.J., Wei, J., and Huang, N.C. 1995. Nitric oxide synthase inhibitor $\mathrm{N}^{\mathrm{G}}$-nitro-L-arginine methyl ester decreases ischemic damage in reversible focal cerebral ischemia in hyperglycemic rats. Brain Res. 677:204-212.

40. Gunasekar, P.G., Kanthasamy, A.G., Borowitz, J.L., and Isom, G.E. 1995. NMDA receptor activation produces concurrent generation of nitric oxide and reactive oxygen species: implication for cell death. J. Neurochem. 65:2016-2021.

41. McQuillan, L.P., Leung, G.K., Marsden, P.A., Kostyk, S.K., and Kourembanas, S. 1994. Hypoxia inhibits expression of endothelial constitutive NOS via transcriptional and post-transcriptional mechanisms. Am. J. Physiol. 267:H1921-H1927.

42. Melillo, G., et al. 1995. A hypoxia-responsive element mediates a novel pathway of activation of the inducible nitric oxide synthase promoter. J. Exp. Med. 182:1683-1693.

43. Wright, G., Higgin, J.J., Raines, R.T., Steenbergen, C., and Murphy, E. 2003. Activation of the prolyl hydroxylase oxygen-sensor results in induction of GLUT1, heme oxygenase-1, and nitric-oxide synthase proteins and confers protection from metabolic inhibition to cardiomyocytes. J. Biol. Chem. 278:20235-20239.

44. Shaul, P.W., et al. 1995. Prolonged in vivo hypoxia enhances nitric oxide synthase Type 1 and Type III gene expression in adult rat lung. Am. J. Respir. Cell Mol. Biol. 13:167-174.

45. Reiser, P.J., Kline, W.O., and Vaghy, P.I. 1997. Induction of neuronal type nitric oxide synthase in skeletal muscle by chronic electrical stimulation in vivo. J. Appl. Physiol. 82:1250-1255.

46. Sharma, H.S., et al. 1996. Involvement of nitric oxide in the pathophysiology of acute heat stress in the rat. Influence of a new antioxidant compound H-290. Ann. N. Y. Acad. Sci. 51:581-590.

47. Wang, Y., Newton, D.C., and Marsden, P.A. 1999. Neuronal NOS: gene structure, mRNA diversity, and functional relevance. Crit. Rev. Neurobiol. 13:21-43

48. Silvagno, F., Xia, H., and Bredt, D.S. 1996. Neuronal nitric-oxide synthase- $\mu$, an alternatively spliced isoform expressed in differentiated skeletal muscle. J. Biol. Chem. 271:11204-11208.

49. Fujisawa, H., et al. 1994. Expression of two types of nitric oxide synthase mRNA in human neuroblastoma cell lines. J. Neurochem. 63:140-145.

50. Xie, J., Roddy, P., Rife, T.K., Murad, F., and Young, P. 1995. Two closely linked but separable promoters for human neuronal nitric oxide synthase gene transcription. Proc. Natl. Acad. Sci. U. S. A. 92:1242-1246.

51. Saur, D., Seidler, B., Paehge, H., Schusdziarra, V., and Allescher, H.-D. 2002. Complex regulation of human neuronal nitric-oxide synthase exon $1 \mathrm{c}$ gene transcription. J. Biol. Chem. 277:25798-25814.

52. Saur, D., et al. 2004. Single-nucleotide promoter polymorphism alters transcription of neuronal nitric oxide synthase exon 1c in infantile hypertrophic pyloric stenosis. Proc. Natl. Acad. Sci. U. S. A. 101:1662-1667.

53. Deans, Z., et al. 1996. Differential regulation of the two neuronal nitric-oxide synthase gene promoters by the Oct- 2 transcription factor. J. Biol. Chem. 271:32153-32158.

54. Weber, J.R.M., and Skene, J.H.P. 1997. Identification of a novel repressive element that contributes to neuron-specific gene expression. J. Neurosci. 17:7583-7593.

55. Sasaki, M., et al. 2000. Dynamic regulation of neuronal NO synthase transcription by calcium influx through a CREB family transcription factordependent mechanism. Proc. Natl. Acad. Sci. U. S. A. 97:8617-8622.

56. Antequera, F., and Bird, A. 1993. Number of CpG islands and genes in human and mouse. Proc. Natl. 
Acad. Sci. U. S. A. 90:11995-11999.

57. Freeland, K., Boxer, L.M., and Latchman, D.S. 2001. The cyclic AMP response element in the $\mathrm{Bcl}-2$ promoter confers inducibility by hypoxia in neuronal cells. Brain Res. Mol. Brain Res. 92:98-106.

58. Beitner-Johnson, D., Rust, R.T., Hsieh, T.C., and Millhorn, D.E. 2001. Hypoxia activates Akt and induces phosphorylation of GSK-3 in PC12 cells. Cell Signal. 13:23-27.

59. Norris, M.L., and Milhorn, D.E. 1995. Hypoxiainduced protein binding to $\mathrm{O} 2$-responsive sequences on the tyrosine hydroxylase gene. J. Biol. Chem. 270:23774-23779

60. Hartsfield, C.L., Alam, J., and Choi, A.M. 1999. Differential signaling pathways of HO- 1 gene expression in pulmonary and systemic vascular cells. Am. J. Physiol. 277:L1133-L1141.

61. Wiesener, M.S., et al. 2001. Constitutive activation of hypoxia-inducible genes related to overexpression of hypoxia inducible factor-1 alpha in clear cell renal carcinomas. Cancer Res. 61:5215-5222.

62. Hagen, T., Taylor, C.T., Lam, F., and Moncada, S.
2003. Redistribution of intracellular oxygen in hypoxia by nitric oxide: effect on HIF1alpha. Science. 302:1975-1978.

63. Metzen, E., Zhou, J., Jelkmann, W., Fandrey, J., and Brune, B. 2003. Nitric oxide impairs normoxic degradation of HIF-1alpha by inhibition of prolyl hydroxylases. Mol. Biol. Cell. 14:3470-3481.

64. Kaelin, W.G. 2005. Proline hydroxylation and gene expression. Annu. Rev. Biochem. 74:115-128.

65. Tennyson, C.N., Klamut, H.J., and Worton, R.G. 1998. The human dystrophin gene requires 16 hours to be transcribed and is cotranscriptionally spliced. Nat. Genet. 9:898-902.

66. Lang, K.J., Kappel, A., and Goodall, G.J. 2002. Hypoxia-inducible factor-1alpha mRNA contains an internal ribosome entry site that allows efficient translation during normoxia and hypoxia. Mol. Biol. Cell. 13:1792-1801.

67. Blais, J.D., et al. 2004. Activating transcription factor 4 is translationally regulated by hypoxic stress. Mol. Cell. Biol. 24:7469-7482.

68. Robb, G.B., et al. 2004. Post-transcriptional regula- tion of endothelial nitric-oxide synthase by an overlapping antisense mRNA transcript. J. Biol. Chem. 279:37982-37996.

69. Teichert, A.-M., et al. 2000. In vivo expression profile of an endothelial nitric oxide synthase promoter-reporter transgene. Am. J. Physiol. Heart Circ. Physiol. 278:H1352-H1361.

70. Bornes, S., et al. 2004. Control of the vascular endothelial growth factor internal ribosome entry site (IRES) activity and translation initiation by alternatively spliced coding sequences. J. Biol. Chem. 279:18717-18726.

71. Paulous, S., Malnou, C.E., Michel, Y.M., Kean, K.M., and Borman, A.M. 2003. Comparison of the capacity of different viral internal ribosome entry segments to direct translation initiation in poly(A)dependent reticulocyte lysates. Nucleic Acids Res. 31:722-733.

72. Stoneley, M., Paulin, F.E., Le Quesne, J.P., Chappell, S.A., and Willis, A.E. 1998. C-Myc 5' untranslated region contains an internal ribosome entry segment. Oncogene. 16:423-428 